\title{
Valoración de las relaciones de Rickettsemia de Anaplasma marginale con factores agroecológicos y productivos en bovinos doble propósito en sabanas inundables del Arauca, Colombia
}

\author{
Evaluation of the Rickettsemia relationships of Anaplasma marginale with \\ agroecological and productive factors in double purpose cattle in \\ flooded savannas of Arauca, Colombia
}

\begin{abstract}
Arcesio Salamanca-Carreño, ${ }^{1,4}$, Rita Tamasaukas ${ }^{2}$, Julio Cesar Giraldo-Forero ${ }^{3}$, Alex Darío Quintero', Milena Esney Hernandez ${ }^{1}$
\end{abstract}

\section{Resumen}

\begin{abstract}
El objetivo del estudio fue determinar la relación existente entre la rickettsemia de $A$. marginale y las interacciones agroambientales y genéticas en bovinos de doble propósito en Arauca, Colombia. Se tomaron muestra de sangre a 269 hembras de 14 fincas, tanto en la época seca como de lluvias y fueron analizadas con las técnicas de Wright y Hemacolor ${ }^{\circledR}$. Se evaluó la interacción entre la presencia de $A$. marginale con las variables grupo racial, época del año, edad y número de partos, mediante el análisis de varianza. Se encontró $66.6 \%$ de animales positivos en la época seca y $100 \%$ en la época lluviosa para A. marginale ( $\mathrm{p}<0.001)$, presentando valores de rickettsemia entre 0 y $0.14 \%$ (promedio: $0.04 \%)$. La rickettsia $A$. marginale presentó interacción con el grupo racial $(\mathrm{p}<0.05)$, siendo más resistentes los animales criollos y cruces de Pardo Suizo x cebú y de Simmental x cebú y susceptibles los animales con predominio Bos taurus. La edad, numero de parto, condición corporal y época no fueron dependientes para la rickettsemia.
\end{abstract}

Palabras clave: hemotrópicos, clima tropical, parásitos intraeritrocíticos, sanidad animal, producción bovina

\footnotetext{
${ }^{1}$ Grupo de Investigaciones Los Araucos, Facultad de Medicina Veterinaria y Zootecnia, Universidad Cooperativa de Colombia sede Arauca, Colombia

${ }^{2}$ Laboratorio de Biotecnología, Investigación y Prestación de Servicios en Sanidad Animal (LABIPRESAN), Universidad Nacional Experimental de los Llanos Centrales Rómulo Gallegos (UNERG), San Juan de los Morros, estado Guárico, Venezuela

${ }^{3}$ Grupo de Investigación en Parasitología y Microbiología Tropical, Facultad de Ingenierías, Administración y Ciencias Básicas, Universidad INCCA de Colombia, Bogotá, Colombia

${ }^{4}$ E-mail: asaca_65@yahoo.es
}

Recibido: 6 de mayo de 2019

Aceptado para publicación: 2 de junio de 2020

Publicado: 11 de agosto de 2020 
The aim of this study was to determine the relationship between the rickettsemia of A. marginale and environmental and genetic interactions in dual-purpose cattle in Arauca, Colombia. Blood samples were taken from 269 females from 14 farms, both in the dry and rainy seasons, and were analysed with the Wright and Hemacolor ${ }^{\circledR}$ techniques. The interaction between the presence of $A$. marginale with the variables breed type, season, age and parity was evaluated by analysis of variance. Resulted showed that $66.6 \%$ of positive animals to $A$. marginale were found in the dry season and $100 \%$ in the rainy season $(\mathrm{p}<0.001$ ), presenting rickettsemia values between 0 and $0.14 \%$ (average: $0.04 \%$ ). The rickettsia $A$. marginale showed interaction with the breed type $(\mathrm{p}<0.05)$, the creole animals and crosses of Brown Swiss x zebu and Simmental x zebu being more resistant, whereas Bos taurus animals were more susceptible. Age, parity number, body condition and season were not dependent on rickettsemia.

Keywords: haemotropic, tropical climate, intraerythrocytic parasites, animal health, bovine production

\section{INTRODUCCIÓN}

La anaplasmosis bovina es una enfermedad hemotrópica cuyo agente causal en Colombia es Anaplasma marginale, rickettsia intraeritrocítica, prevalente en el departamento de Córdova (20.6\%) y con valores de parasitemia o rickettsemia del $11.2 \%$ (Blanco et al., 2016); similar a la frecuencia hemoparasitaria de $22.5 \%$ hallado por Herrera et al. (2008) para el bajo Cauca antioqueño y alto San Jorge (Córdoba), donde el 59.3\% correspondió a Anaplasma spp; en tanto que Calderón et al. (2016) reportaron $27.7 \%$ de anaplasmosis, $19.4 \%$ de babesiosis y $2.3 \%$ de tripanosomiasis en bovinos de Antioquia, Córdoba y Sucre, indicando la endemicidad en esta región para los hemotrópicos.

La transmisión del Anaplasma es causada por artrópodos (tábanos y garrapatas) y en forma iatrogénica durante procesos de vacunación masiva, común en Latinoamérica (Eleizalde y Reyna-Bello, 2014). En un predio en el estado Guárico, Venezuela, Eleizalde et al. (2007) observaron $47 \%$ de prevalencia de anaplasmosis. En forma similar, Luzarraga (2012) detectaron $39 \%$ de casos positivos para $A$. marginale, y Muñoz et al. (2014) reportaron prevalencias cercanas al $50 \%$, en ambos casos, en fincas ecuatorianas. Los animales afectados por la rickettsemia manifiestan pérdida de peso, debilidad, disminución de los movimientos ruminales, palidez en mucosas y fiebre de $40.5^{\circ} \mathrm{C}$ por varios días o semanas (Márquez-Lara y García-Castro, 2003).

Las características climáticas y medioambientales de humedad, temperatura y luminosidad, propia de las regiones tropicales propician nichos ecológicos para el desarrollo de artrópodos como garrapatas (Rhiphicephalus [Boophilus]) microplus, Amblyomma cajennense), moscas picadoras (Stomoxys calcitrans) y tábanos (Tabanus nebulosus), vectores biológicos de hematozoarios causantes de parasitosis hemotrópicas (Prada y Crespo, 2006; Benavides et al., 2012a). El cambio climático ha generado alteraciones en los regímenes de lluvia y los patrones de temperatura, lo que ha permitido cambios en la frecuencia y distribución de los vectores biológicos en la mayoría de las regiones tropicales y subtropicales, incluyendo los hábitats de garrapatas transmisoras de hemotrópicos (Cortés, 2010). 
La mayoría de los reportes enfatizan en valores porcentuales de prevalencia y en menor proporción sobre la interacción entre los factores genéticos y ambientales asociados a la rickettsemia. Como en la mayoría de las regiones tropicales, en el departamento de Arauca son frecuentes las enfermedades causadas por la presencia de ecto y endoparásitos en los bovinos (Bos taurus y Bos indicus) domésticos. La introducción de razas exóticas (Holstein, Pardo Suizo, Simmental, Jersey, entre otras) de mayor susceptibilidad para padecer enfermedades anemizantes frente a los recursos genéticos adaptados hace necesario el conocimiento del comportamiento epidemiológico de estas enfermedades, importante para su diagnóstico y control oportuno (González y Meléndez, 2007). Por tanto, el objetivo del presente estudio fue determinar la relación existente entre la rickettsemia de $A$. marginale y las interacciones agroambientales y genéticas en bovinos hembra en ordeño bajo un sistema de producción de doble propósito en el municipio de Arauca, Colombia

\section{Materiales y Métodos}

\section{Zona de Estudio}

El estudio se realizó en el municipio de Arauca, localizado al oriente del departamento del mismo nombre. Es una región de sabana inundable, con una topografía plana típica de llanura, de una extensión de 587000 ha, dividida en cinco corregimientos y 56 veredas. La población ganadera es de 300085 animales distribuidos en 1393 predios (ICA, 2019). El régimen de lluvias es básicamente monomodal, con una época seca o verano (noviembre-abril), y una época lluviosa o invierno (mayo-octubre). En general, la precipitación anual es inferior a $1500 \mathrm{~mm}$. El Municipio de Arauca se encuentra a $128 \mathrm{msnm}$, con temperatura ambiental de $35^{\circ} \mathrm{C}$ en marzo hasta $19^{\circ} \mathrm{C}$ en enero, humedad relativa de $65 \%$ en marzo y $85 \%$ en junio-julio (IDEAM, 2000; Arauca, 2019). La región, de acuerdo con la clasificación de Holdridge, corresponde a la zona de bosque subhúmedo tropical (Holdridge, 1987).

\section{Manejo Animal}

Los predios pertenecen a pequeños productores con escaso nivel tecnológico, cuya principal actividad es el ordeño manual con presencia del ternero, y producen leche para la elaboración de quesos artesanales y para la venta directa. El tipo de explotación es extensivo, sistema tradicional de la sabana inundable, pocas fincas manejan rotación de potreros y en época de verano algunas cuentan con disponibilidad de agua en los potreros, en tanto los animales de otras fincas tienen que recorrer largas distancias para acceder al agua. Los animales pastorean en potreros cubiertos en su mayoría por gramíneas y leguminosas nativas.

Los animales usualmente reciben sal blanca $(\mathrm{NaCl})$ y en menor proporción sales mineralizadas. Los esquemas de desparasitación no son frecuentes y se fundamenta en la administración de lactonas-macrocíclicas, albendazoles y baños ectoparasiticidas basados en cipermetrinas, siendo frecuente los reportes de presencia de garrapatas, moscas y tábanos en los predios.

La población bovina evaluada fue constituida por animales con proporciones Bos indicus - Bos taurus indefinidas. Al carecer de registros genealógicos, la clasificación de los grupos raciales se basó en características fenotípicas de acuerdo lo recomendado por otros autores (López y Vaccaro, 2002; Sheen y Riesco, 2002). e información suministrada por los ganaderos (Salamanca-Carreño et al., 2018).

\section{Muestra Poblacional}

Muestras de sangre fueron colectadas a 269 bovinos hembra, de edades varias, pertenecientes a 14 fincas ganaderas de doble propósito y que se encontraban en ordeño. 
Los tipos raciales estuvieron representados por: cebú $(\mathrm{n}=105)$, criolla $(\mathrm{n}=14)$, criolla $\mathrm{x}$ cebú $(\mathrm{n}=27)$, mestiza $(\mathrm{n}=59)$, Pardo $\mathrm{x}$ cebú $(\mathrm{n}=21)$, Bos taurus puro $(\mathrm{n}=23)$, Simmental $\mathrm{x}$ cebú $(\mathrm{n}=15)$ y Holstein $\mathrm{x}$ cebú $(\mathrm{n}=5)$.

Para la recolección de la información y toma de las muestras se contó con el consentimiento del propietario y mediante entrevista se indagó aspectos que permitió caracterizar los animales seleccionados, así como garantizar que no se hubieran recibido tratamiento para hemotrópicos en el trimestre previo al estudio. Se registró información sobre tipo racial, edad, número de partos y condición corporal. El muestreo fue durante 12 meses (octubre de 2015 - octubre de 2016) a fin de abarcar las dos épocas climáticas. El muestreo de las fincas se realizó por conveniencia (Ortega y de Blas, 1998; Forlano et al., 2012).

La muestra de sangre $(4 \mathrm{ml})$ se extrajo por punción de la vena coccígea media en tubos Vacutainer ${ }^{\circledR}$ con anticoagulante (EDTA). Las muestras fueron almacenadas en condiciones de refrigeración (Ortiz, 2014), y transportadas al Laboratorio de Ciencias Básicas Biomédicas de la Facultad de Medicina Veterinaria y Zootecnia de la Universidad Cooperativa de Colombia, sede Arauca. Las muestras fueron procesadas mediante la técnica de frotis de sanguíneo completo y tinción con Wright y Hemacolor ${ }^{\circledR}$ (Merck, 2016); la valoración microscópica se realizó por duplicado y doble ciego para el diagnóstico de hemotrópicos.

Se define rickettsemia como la cuantificación de los valores de formas parasitarias observadas en los glóbulos rojos infectados por la rickettsia Anaplasma marginale, a fin de diferenciarla del término "parasitemia» que aplica a las especies de hemoprotozoarios u otros parásitos hemáticos. La rickettsemia mide la intensidad o densidad de la infección de la rickettsia en sangre. Para la determinación de la rickettsemia se siguió el método reportado por Benavides (2008) y
Benavides et al. (2012a), siendo que: \% Parasitemia $=(\mathrm{GRP} / \mathrm{GRT}) * 100$, donde GRP $=$ Glóbulos rojos parasitados en 20 campos microscópicos, GRT $=$ Glóbulos rojos totales en 20 campos microscópicos.

\section{Análisis Estadístico}

Se utilizó un análisis descriptivo mediante tablas de frecuencia para determinar la cantidad porcentual de animales positivos para A. marginale por época del año. Se utilizó el análisis de varianza para determinar la relación existente entre la presencia de $A$. marginale con las variables grupo racial, época del año, edad y número de partos, con un nivel de significación del 5\%. Las muestras de tamaño desigual analizaron según lo reportado por Lozano-Rivas (2011). Los datos se procesaron con el paquete estadístico Statistic 8.0 (2018).

\section{Aspectos Éticos}

Los aspectos éticos del presente artículo se encuentran orientados por la Resolución 8430 de 1993 del Ministerio de Salud de Colombia, que establece las normas científicas, técnicas y administrativas para la investigación en salud (República de Colombia, 1993).

\section{Resultados y Discusión}

\section{Prevalencia y Rickettsemia General}

La prevalencia de Anaplasma marginale en época seca y de lluvia fue de $5.39 \mathrm{y}$ $33.95 \%$, respectivamente $(\mathrm{p}<0.05)$ (Cuadro $1)$. Estos valores fueron inferiores a la prevalencia de $67 \%$ reportada en fincas de Venezuela (Florio-Luis et al., 2012), mediante el frotis de capa blanca coloreados con Giemsa al 10\%. La literatura reporta que la presencia de $A$. marginale es frecuente en los hatos donde existe un inadecuado control de vectores (Oliveira et al., 2011), situación que puede estar ocurriendo en el presente 
Cuadro 1. Prevalencia de Anaplasma marginale en hembras bovinas de 14 fincas doble propósito en el municipio Arauca, Colombia

\begin{tabular}{llcc}
\hline \multirow{2}{*}{ Época del año } & Tipo racial & $\begin{array}{c}\text { Animales } \\
(\mathrm{n})\end{array}$ & $\begin{array}{c}\text { Prevalencia } \\
(\%)\end{array}$ \\
\hline \multirow{2}{*}{ Seca } & Mestiza & 14 & $7.14^{\mathrm{a}}$ \\
& Criollo x cebú & 20 & $5.00^{\mathrm{a}}$ \\
& Pardo x cebú & 14 & $14.29^{\mathrm{b}}$ \\
& Criolla & 9 & $0^{\mathrm{c}}$ \\
& Cebú & 51 & $5.88^{\mathrm{a}}$ \\
& Simmental x cebú & 4 & $0^{\mathrm{c}}$ \\
\hline \multirow{2}{*}{ Lluvias } & & 112 & $5.39^{\mathrm{h}}$ \\
& Mestiza & 45 & $31.11^{\mathrm{a}}$ \\
& Criollo x cebú & 7 & $42.86^{\mathrm{b}}$ \\
& Pardo x cebú & 7 & $0.14^{\mathrm{c}}$ \\
& Criolla & 5 & $20.00^{\mathrm{d}}$ \\
& Cebú & 54 & $31.48^{\mathrm{a}}$ \\
& Simmental x cebú & 11 & $18.18^{\mathrm{e}}$ \\
& Holstein x cebú & 5 & $80.00^{\mathrm{f}}$ \\
& Bos taurus puro & 23 & $47.83^{\mathrm{b}}$ \\
\hline Subtotal & & 157 & $33.95^{\mathrm{i}}$ \\
\hline Total & & 269 & 21.71 \\
\hline
\end{tabular}

$a, b, c, d, e, f$, Letras diferentes en columnas indican diferencia significativa $(p<0.05)$

$h, i$ : Letras diferentes en subtotales indican diferencia significativa $(p<0.05)$

Los promedios entre épocas (subtotales) fueron estadísticamente diferentes $(p<0.05)$

estudio. Otros agentes hemotrópicos observados fueron Babesia spp y Trypanosoma vivax, sin que se haya presentado casos de coinfección de dos o tres agentes etiológicos.

Eleizalde y Reyna-Bello (2014) indican que una vez que un bovino sobrepasa la etapa aguda de la anaplasmosis, la rickettsemia disminuye y los ciclos se hacen crípticos, al presentar menos de un eritrocito infectado por cada 10000 , por lo que el animal se trasforma en persistente infectado (PI) por periodos que pueden superar los cinco años. $A$. marginale, para escaparse del sistema inmune y permanecer de manera persistente en el hospedador, logra cambiar la secuencia aminoacídica de algunas proteínas de la membrana externa por variabilidad antigénica, para lo cual, utiliza cuatro mecanismos diferentes, maximizando la estructura genética del genoma (Camacho et al., 2000; De La Fuente et al., 2004).

En la Amazonia colombiana se han reportado prevalencias de $11.2 \%$ de $A$. marginale, sin notar la presencia de Babesia sp y Trypanosoma spp (Rodríguez et al., 2011), mientras que en la región del bajo Cauca y Alto San Jorge se determinaron valores del $23.5 \%$, siendo A. marginale el 
hemotrópico de mayor presencia (Herrera et al., 2008). En otros estudios, se reportan prevalencias de $7 \%$ en el piedemonte amazónico colombiano (Orjuela-Cháves et al., 2015), de 11.6 y $3.9 \%$ para A. marginale y $B$. bigemina, respectivamente, en Arauca (Useche, 2010) y de $27.7 \%$ en la región del Caribe (Calderón et al., 2016).

Asimismo, en fincas de doble propósito de Venezuela se registraron prevalencias entre 62 y $90 \%$ de $A$. marginale, en frotis de capa blanca coloreados (Tamasaukas et al., 2010) y de $89.1 \%$ en el Noreste de Brasil empleando la técnica de PCR (Souza et al., 2013). Otros estudios en Ecuador revelan prevalencias de $68 \%$ (Muñoz et al., 2014) y 85.4\% (Escobar et al., 2015), utilizando una variedad de pruebas diagnósticas. Las diferencias encontradas para las prevalencias en regiones endémicas para hemotrópicos pueden obedecer, entre otros aspectos, a la sensibilidad y especificidad de las técnicas empleadas, la edad de los animales muestreados, la presencia de animales portadores de la ricketsia, factores climatológicos y de producción (tales como prácticas de descorne, castraciones, inyecciones, entre otros) (INTA, 2010).

El control de artrópodos no es práctico en muchas áreas y solo puede prevenir parcialmente la transmisión de $A$. marginale, que ocurre tanto por transmisión mecánica de sangre infectada a través de insectos y fómites, como por transmisión biológica a través de garrapatas (Kocan et al., 2003).

La detección de $A$. marginale, especialmente durante la fase aguda, puede realizarse en el laboratorio, mediante la revisión de frotis sanguíneos utilizando colorantes comerciales, tales como Diff Quick Stain, Giemsa y Acridina Naranja, donde se puede observar un cuerpo denso en la periferia de los glóbulos rojos (Díaz et al., 2003). En el estado de portador es difícil la observación de los organismos en un frotis sanguíneo, por lo que se recomienda el empleo de técnicas serodiagnósticas como Fijación del Complemento, ELISA e Inmunofluorescencia Indirecta (IFI) o la Reacción en Cadena de la Polimerasa (PCR) (Tamasaukas et al., 2010).

El frotis sanguíneo es un método de diagnóstico directo confiable, económico y capaz de detectar niveles de parasitemia de 0.1 a $0.2 \%$, o sea, sólo puede detectar niveles mayores a $10^{6}$ eritrocitos infectados por mililitro de sangre (Gale et al., 1996). En el presente estudio, la concentración de glóbulos rojos fue de $10^{12}$ para la determinación de la rickettsemia, por lo que la sensibilidad de la prueba fue mayor.

Los valores promedios observados de rickettsemia variaron de $0.01 \%$ en época seca a $0.04 \%$ en época de lluvias (Cuadro 2); valores similares a los reportados por Benavides et al. (2012b) quienes señalaron cargas parasitarias (rickettsemia) en fincas del Valle del Sinú (Montería), Colombia, entre 0.01 a $0.05 \%$ para $A$. marginale. En tanto, Benavides y Polanco (2017) encontraron valores que fluctuaron entre 0.001 y $0.6 \%$ de rickettsemia.

El ganado que sobrevive a la infección aguda desarrolla infecciones persistentes caracterizadas por rickettsemia cíclica de bajo nivel (French et al., 1999; Corona et al., 2004), tal como fue observado en el presente estudio. El sistema inmune del hospedador es incapaz de eliminar completamente la infección en la fase crónica de la enfermedad, posiblemente debido a la variabilidad antigénica de este microorganismo. Se ha visto que tanto en la fase aguda como en la crónica hay un comportamiento de aumento $\mathrm{y}$ disminución de los niveles de eritrocitos infectados, lo cual sugiere que participan los mismos mecanismos de respuesta primaria del hospedero para controlar ambos ciclos de rickettsemia (Kieser et al., 1990). 
El ganado infectado persistentemente sirve como reservorio de $A$. marginale porque proporciona una fuente de sangre infecciosa para la transmisión mecánica y biológica por las garrapatas. La transmisión de $A$. marginale puede realizarse mecánicamente por picaduras de insectos hematófagos o fómites contaminados con sangre y por transmisión biológica mediante garrapatas. $\mathrm{La}$ transmisión mecánica se produce con frecuencia a través de fómites contaminados con sangre, incluidas agujas, sierras para descornar, pinzas nasales, instrumentos para tatuar, dispositivos para marcar las orejas e instrumentos de castración. Se ha informado de la transmisión mecánica por los dípteros hematófagos de los géneros Tabanus, Stomoxys y mosquitos. Esta forma de transmisión mecánica se considera la ruta principal de diseminación de $A$. marginale en áreas de América Central y del Sur y África donde no se producen vectores de garrapatas. (Kocan et al., 2003: INTA, 2014).

\section{Prevalencia por Tipo Racial}

La prevalencia de $A$. marginale, por tipo racial se presenta en el Cuadro 1. Los mayores valores de prevalencia en la época seca se observaron en los tipos raciales Pardo Suizo x cebú, mestiza y cebú, siendo negativos en el criollo y en el cruce de Simmental x cebú; mientras que en la época de lluvias se presentaron en los tipos raciales Holstein x cebú, puro Bos taurus, criollo x cebú, cebú y Simmental x cebú (Cuadro 1). En investigaciones realizas en Bolivia en bovinos mestizos cebú se reporta $6.9 \%$ del ganado infectado con A. marginale (Mercado et al., 2011), en tanto que, en la región del Bajo Cauca, los animales mestizos presentaron $23.8 \%$ de seropositividad para $A$. marginale (Herrera et al., 2008), porcentaje inferior a los valores hallados en el presente estudio para este tipo racial en época de lluvias.

Las razas Bos taurus (Holstein, Brown Swiss o Hereford) son más propensas a desarrollar anaplasmosis aguda que las cebuinas cruzadas o el ganado criollo (Aguirre et al., 1988). Guglielmone (1995) manifiesta que las razas lecheras, debido al desgaste y al estrés continuo al que son sometidos durante la lactancia, son más propensas a padecer la enfermedad. En forma similar, Herrera et al. (2008) indican que la raza es un factor importante en la infección con hemoparásitos, pues los bovinos dedicados a la explotación de leche y sus cruces son más susceptibles que las razas tipo carne, debido a una mayor susceptibilidad a las garrapatas y al hemoparásito. No obstante, Muñoz-Guarnizo et al. (2017) no observaron diferencia significativa entre grupos raciales en la provincia de Zamora Chinchipe, Ecuador.

La prevalencia de $A$. marginale para el grupo cebú fue superior a lo reportado para la región de Córdoba para bovinos Gyr quienes presentaron una frecuencia de $24.4 \%$ de positivos para hemotrópicos (Blanco et al., 2016). Por otro lado, investigaciones en el Caribe colombiano reportaron valores contradictorios; así, Calderón et al. (2016) reportaron una prevalencia de $23.6 \%$ en mestizos y $16.8 \%$ en cebúes, mientras que Vargas y Salamanca (2013) reportaron $100 \%$ de prevalencia de esta rickettsia en ganado criollo.

\section{Interacciones}

Tipo racial y prevalencia de A. marginale

La mayor susceptibilidad para $A$. marginale se halló en el tipo racial Holstein x cebú y Puro Bos taurus (Cuadro 1), atribuido a la influencia genética del Bos taurus. Es reconocido que los animales $B$. indicus son más resistentes a los ectoparásitos que los B. taurus (Bianchini et al., 2007). Constantino et al. (2010) demostraron una mayor reacción granulocítica (mayor número de glóbulos blancos) en bovinos Bos taurus (individuos susceptibles) en comparación con individuos Bos indicus ante un ataque de garrapatas. 
Cuadro 2. Parasitemia de Anaplasma marginale en hembras bovinas de 14 fincas doble propósito en el municipio Arauca, Colombia, según tipo racial, edad, condición corporal y número de partos

\begin{tabular}{|c|c|c|c|c|c|c|}
\hline Época & Tipo racial & $\begin{array}{c}\text { Animales } \\
\text { (n) }\end{array}$ & $\begin{array}{c}\text { Anaplasma } \\
\text { marginale } \\
(\%)\end{array}$ & $\begin{array}{c}\text { Edad } \\
\text { (años) }\end{array}$ & $\begin{array}{l}\text { Número } \\
\text { de partos }\end{array}$ & $\begin{array}{l}\text { Condición } \\
\text { corporal } \\
\text { (CC) }\end{array}$ \\
\hline \multirow[t]{6}{*}{ Seca } & Mestiza & 14 & 0.01 & 6.3 & 2.7 & 3.1 \\
\hline & Criollo x cebú & 20 & 0.00 & 6.1 & 2.4 & 3.0 \\
\hline & Pardo x cebú & 14 & 0.03 & 5.8 & 2.5 & 3.1 \\
\hline & Criolla & 9 & 0.00 & 6.7 & $3.3^{\mathrm{b}}$ & 3.1 \\
\hline & Cebú & 51 & 0.01 & 6.5 & 2.7 & 3.1 \\
\hline & $\begin{array}{l}\text { Simmental x } \\
\text { cebú }\end{array}$ & 4 & 0.00 & $7.3^{\mathrm{a}}$ & 2.8 & 3.0 \\
\hline \multicolumn{2}{|c|}{ Sub-total } & 112 & 0.01 & 6.4 & 2.7 & 3.1 \\
\hline \multirow[t]{8}{*}{ Lluvias } & Mestiza & 45 & 0.06 & 6.5 & 2.4 & 3.0 \\
\hline & Criollo x cebú & 7 & $0.14^{\mathrm{a}}$ & $7.0^{\mathrm{a}}$ & 2.3 & 2.9 \\
\hline & Pardo x cebú & 7 & 0.03 & $7.4^{\mathrm{a}}$ & $3.2^{\mathrm{b}}$ & 3.9 \\
\hline & Criolla & 5 & 0.02 & 6.3 & $1.8^{\mathrm{a}}$ & 3.2 \\
\hline & Cebú & 54 & 0.06 & 6.9 & 2.3 & 3.2 \\
\hline & $\begin{array}{l}\text { Simmental x } \\
\text { cebú }\end{array}$ & 11 & $0.08^{\mathrm{b}}$ & 6.7 & 2.6 & 2.8 \\
\hline & Holstein $x$ cebú & 5 & $0.09^{b}$ & 6.5 & 2.5 & 3.3 \\
\hline & Puro B. taurus & 23 & $0.08^{\mathrm{b}}$ & $7.5^{\mathrm{a}}$ & $3.0^{\mathrm{b}}$ & 3.0 \\
\hline \multicolumn{2}{|c|}{ Sub- total } & 157 & 0.06 & 6.8 & 2.5 & 3.2 \\
\hline \multicolumn{2}{|c|}{ Total } & 269 & 0.04 & 6.7 & 2.6 & 3.1 \\
\hline
\end{tabular}

$a, b$ Letras diferentes en columnas indican diferencia significativa $(p<0.05)$

Tipo racial y rickettsemia de A. marginale

Se hallaron diferencias para tipo racial $(\mathrm{p}<0.001)$, siendo de mayor susceptibilidad el criollo x cebú, Holstein x cebú, Simmental x cebú y Bos taurus puro (Cuadro 2).

\section{Época y rickettsemia de A. marginale}

La rickettsemia de animales infectados con $A$. marginale presentó dependencia relacionada con la época del año $(\mathrm{p}<0.05)$ (Cua- dro 2), toda vez que hubo un mayor número de casos y elevada carga parasitaria para este hemotrópico en la época de lluvias. Estos resultados divergen de los obtenidos en otros estudios que indican mayores valores para la época seca (Bastardo et al., 2012; Calderón et al., 2016). En la época de menor precipitación hay menor disponibilidad de forraje, se incrementa la cobertura arbórea y la presencia de vectores biológicos y mecánicos como garrapatas y moscas al reducirse los factores ambientales que afectan la supervivencia 
de dichos artrópodos (Salazar-Benjumea, 2015). Por otro lado, se observó que los mayores valores de rickettsemia fue en la época de lluvias, coincidente con otras publicaciones (Tamasaukas et al., 2010, 2014; Salamanca-Carreño et al., 2018). Lo anterior podría argumentarse que, en la época de mayor pluviosidad en la sabana araucana, se incrementa la población de insectos hematófagos antes que la de garrapatas, como transmisores potenciales de afecciones hemotrópicas.

Número de partos y rickettsemia de A. marginale

Se encontró una mayor rickettsemia de A. marginale en vacas con dos o más partos $(\mathrm{p}<0.001)$ (Cuadro 2) en época de lluvias en los grupos raciales criollo x cebú $(0.14)$, Simmental x cebú (0.08), Holstein x cebú (0.09) y puro Bos taurus (0.08), lo que podría estar relacionado con el mayor tiempo de exposición al parásito.

\section{Edad y rickettsemia de A. marginale}

No se encontró dependencia de $A$. marginale con respecto a la edad de los animales, aunque los animales Simmental x cebú con edades superiores a los 7 años tuvieron una mayor rickettsemia (Cuadro 2). Por otro lado, se argumenta que, en la mayoría de las enfermedades transmitidas por garrapatas, los animales jóvenes son más resistentes en comparación con los de mayor edad; o bien, pueden ser susceptibles a la infección, pero la presentación de la enfermedad es de menor gravedad (Ríos et al., 2010; SalamancaCarreño et al, 2018). En relación con la edad, se estableció que para la zona de Turipana, área endémica en Colombia, la edad de primoinfección con $A$. marginale, varía de las 4 a las 24 semanas, siendo el promedio de 11 semanas (Betancourt, 1990).
Condición corporal (CC) y rickettsemia de A. marginale

No se halló dependencia de $A$. marginale con respecto a la condición corporal de los animales, salvo en los casos del Pardo Suizo x cebú con una CC de 3.9 versus criollo x cebú quienes presentaron una $\mathrm{CC}$ de 2.9 con la más alta rickettsemia $(13.57 \%$; Cuadro 2). Se deduce que la presencia de hemotrópicos no es evidencia concluyente para la $\mathrm{CC}$, ya que depende de otros factores (Florio-Luis et al., 2012).

\section{Conclusiones}

- La prevalencia de Anaplasma marginale en época seca y de lluvia fue de 5.39 y $33.95 \%$, respectivamente $(\mathrm{p}<0.05)$

- Bovinos de doble propósito en la región de sabana inundable araucana presentaron prevalencias elevadas de hemotrópicos asociado con $A$. marginale en la época de lluvias.

- La prevalencia de rickettsia A. marginale presentó interacción significativa con el grupo racial, siendo más susceptibles los animales con predominio Bos taurus y más resistentes los animales criollos y cruces de Pardo Suizo x cebú y de Simmental $\mathrm{x}$ cebú.

- Los valores de rickettsemia, tanto en la época seca como en la de lluvias, fueron inferiores al $1 \%$, lo que evidencia la condición de inestabilidad enzoótica de la anaplasmosis bovina para los predios evaluados.

\section{Agradecimientos}

Al Comité Nacional de InvestigacionesCONADI de la Universidad Cooperativa de Colombia por el financiamiento de esta investigación; a los productores por facilitar los animales; y a los estudiantes auxiliares de in- 
vestigación de la Facultad de Medicina Veterinaria y Zootecnia por su dedicación al trabajo de campo. A los estudiantes de postgrado del LABIPRESAN-UNERG de la República Bolivariana de Venezuela por los análisis estadísticos, revisión del manuscrito y contribuciones bibliográficas.

\section{Literatura Citada}

1. Aguirre DH, Bermúdez AC, Mangold AJ, Guglielmone AA. 1988. Infección natural con Anaplasma marginale en bovinos de raza Hereford, Criolla y Nelore en Tucumán, Argentina. Rev Latinoam Microbiol 30: 37-42.

2. Arauca. 2019. Clima: Arauca, Aeropuerto Santiago Pérez. [Internet]. Disponible en: https://es.allmetsat.com/cli$\mathrm{ma} /$ venezuela.php? code $=80099$

3. Bastardo Y, Barrios M, Borges, J. 2012. Prevalencia de anticuerpos contra hemoparásitos de acuerdo a la época en mautas de un sistema doble propósito en el estado Yaracuy. Rev CientFac Cien V 22(Supl 1): 83.

4. Benavides OE. 2008. Consideraciones sobre la epidemiología de anaplasmosis y babesiosis de los bovinos, efecto de la estabilidad enzoótica de hatos. Asesoria especializada en parasitología y epidemilogía veterinaria. [Iinternet] Disponible en: https://es.slideshare.net/EVBenavides/epidemiologia-anaplasmosis-ybabesiosis

5. Benavides E, Polanco N, Vizcaíno O, Betancur O. 2012a. Criterios y protocolos para el diagnóstico de hemoparásitos en bovinos. Rev Cienc Anim 5. 31-49.

6. Benavides, E, Vizcaíno, O, Polanco, N, Mestra, A, Betancur, OJ. $2012 b$. Efecto terapéutico de un fármaco frente a los hemoparásitos del bovino Babesia bovis, Babesia bigemina y Anaplasma marginale. Rev CES Med Vet Zootec 7: 33-48.
7. Benavides E, Polanco P. 2017. Epidemiología de hemoparásitos y endoparásitos en bovinos de zonas de reconversión ganadera en La Macarena (Meta, Colombia). Rev Med Vet 34(Supl): 115-136. doi: 10.19052/mv.4260

8. Betancourt E. 1990. Epidemiología de la anaplasmosis en Colombia. Convenio Colombo-Alemán ICA-GTZ, Bogotá (Colombia). En: Seminario Internacional sobre Diagnóstico, Epidemiología y Control de Enfermedades Hemoparasitarias, Palmira, Colombia.

9. Bianchini I, Catto BJ, Kichel NA, Torres AA, Honer MR. 2007. The effect of the control of endo- and ectoparasites on weight gains in crossbred cattle (Bos taurus taurus $\mathrm{x}$ Bos taurus indicus) in the central region of Brazil. Trop Anim Health Prod 39: 287-296. doi: 10.1007/\}

10. Corona B, Rodríguez M, Martínez S. 2004. Anaplasmosis bovina (CENSA). REDVET 6(4). [Internet]. Disponible en: https://www.researchgate.net/publication/255620752_Anaplasmosis_bovina_bovine_anaplasmosis

11. Cortés J. 2010. Cambios en la distribución y abundancia de las garrapatas y su relación con el calentamiento global. Rev Med Vet Zoot 57: 65-75.

12. De la Fuente J, García-García JC, Barbet AF, Blouin EF, Kocan KM. 2004. Adhesion of outer membrane proteins containing tandem repeats of Anaplasma and Ehrlichia species (Rickettsiales: Anaplasmataceae) to tick cells. Vet Microbiol 98: 313-322. doi: 10.1016/j.vetmic.2003.11.001

13. Díaz D, Valera $Z$, de Andrade E, Parra O, Escalona F, Ramírez R. 2003. Prevalencia de Anaplasma marginale en bovinos del Sector La Piñata, Municipio La Cañada de Urdaneta, estado Zulia, Venezuela. Rev Cient-Fac Cien V 13: 193-198.

14. Eleizalde MC, Reyna-Bello A. 2014. Mecanismos de variación antigénica en Anaplasma marginale. Rev Cient Fac Cien V 55: 112-123. 
15. Eleizalde MC, Reyna-Bello A, Caballero H, Vivas J. 2007. Evaluación y mejoramiento del ensayo imunoenzimático (ELISA) para el diagnóstico de la anaplasmosis bovina utilizandola MSP5 recombinante como antígeno. Rev Cient-Fac Cien V 17: 349-356.

16. Escobar A, Cevallos O, Villareal P, Carranza M, Pinargote E. 2015. Prevalencia y detección por PCR anidada de Anaplasma marginale en bovinos y garrapatas en la zona central del Litoral ecuatoriano. Cienc Tecnol 8: 11-17.

17. Florio-Luis J, Tamasaukas R, Rivera S. 2012. Diagnóstico participativo de hemoparásitos en bovinos a nivel de pequeños productores y productoras de ganadería doble propósito en el Sur del Estado Araugua en la República Bolivariana de Venezuela. Act Iberoam Conserv Anim 2: 163-170.

18. Forlano M, Canelón J, Mujica F, Álvarez E, Concepción J, Granda F. 2012. Prevalencia de endoparásitos en caballo criollo venezolano en dos hatos del estado Apure-Venezuela. Gac Cien Vet 17: 11-17.

19. French DM, Brown WC, Palmer GH. 1999. Emergence of Anaplasma marginale antigenic variants during persistent rickettsemia. Infect Immun 67: 5834-5840.

20. Gale RC, Dimmock CM, Gartside M, Leatch $G$ 1996. Anaplasma marginale detection of carrier cattle by PCR. Int J Parasitol 26: 1103-1109.

21. González J, Meléndez R. 2007. Seroprevalencia de la tripanosomosis y anaplasmosis bovina en el municipio Juan José Mora del estado Carabobo, Venezuela, mediante la técnica de ELISA. Rev Cient Fac Cien V 17: 449-455.

22. Guglielmone AA. Epidemiology of babesiosis and anaplasmosis in South and Central America. Vet. Parasitol. 57:109119. doi: 10.1016/0304-4017(94)03115-d

23 Herrera M, Soto A, Urrego V, Rivera G, Zapata M, Ríos L. 2008. Frecuencia de 445 hemoparásitos en bovinos del Bajo Cauca y Alto San Jorge, 2000-2005. Rev MVZ Córdoba 13: 1486-1494.
24 Holdridge LR. 1987. Ecología basada en zonas de vida. San José de Costa Rica: IICA. 216 p.

25. [ICA] Instituto Colombiano Agropecuario. 2019. Censo Pecuario. [Internet]. Disponible en: https://www.ica.gov.co/areas/pecuaria/servicios/ epidemiologia-veterinaria/censos-2016/ censo-2018

26. [IDEAM] Instituto de Hidrología, Meteorología y Estudios Ambientales. 2000. Información aeronáutica. Climatología. [Internet]. Disponible en: http:// bart.ideam.gov.co/cliciu/arauca/precipitacion.htm

27. [INTA] Instituto Nacional de Tecnología Agropecuaria. 2010. Casuística de la babesiosis y anaplasmosis bovina 2009-2010. No 456. [Internet]. Disponible en: https://inta.gob.ar/sites/default/ files/script-tmp-n_456.pdf

28. [INTA] Instituto Nacional de Tecnología Agropecuaria. 2014. Anaplasmosis bovina. Noticias y comentarios. $\mathrm{N}^{\mathrm{o}}$ 515. [Internet]. Disponible en: https://inta.gob.ar/sites/default/files/script-tmpinta_anaplasmosis_bovina_not_y_com_515.pdf

29. Kieser ST, Eriks IS, Palmer GH. 1990. Cyclic rickettsemia during persistent anaplasmosis infection in cattle. Infect Immun 58: 1117-1119.

30. Kocan KM, de La Fuente J, Guglielmone AA, Meléndez RD. 2003. Antigens and alternatives for control of Anaplasma marginale infection in cattle Clin Microbiol Rev 16: 698-712. doi: 10.1128/CMR.16.4.698-712.2003

31. López J, Vaccaro L. 2002. Comportamiento productivo de cruces Holstein Friesian-cebú comparados con Pardo Suizo-cebú en sistemas de doble propósito en tres zonas de Venezuela. Zootec Trop 20: 397-414.

32. Lozano-Rivas, WA. 2011. Determinación del número mínimo de observaciones en investigación, obviando las estimaciones de la varianza de datos. Rev Didáctica Ambiental 10: 54-61. 
33. Luzarraga A. 2012. Incidencia de Anaplasma bovis (Anaplasma marginale) en hatos bovinos de las asociaciones ganaderas del cantón Vinces provincia de Los Ríos. Título de Médico Veterinario Zootecnista. Guayaquil, Ecuador: Univ. de Guayaquil. 52 p.

34. Márquez-Lara, D, García-Castro, F. 2003. Enfermedades hemoparasitarias de importancia en bovinos en Colombia. Corporación Colombiana de Investigación Agropecuaria PNDA. [Internet]. Disponible en: https://repository.agrosavia.co/bitstream/handle/20.500.12324/ 1619/40769_26283.pdf?sequence$=1$ \&isAllowed $=\mathrm{y}$

35. Mercado A, Loza-Murguía M, Aliaga R, Cahuana J. 2011. Frecuencia de Anaplasma marginale (Theiler 1910) y Babesia sp en bovino mestizo cebú, en el Municipio de Ixiamas, provincia Abel Iturralde, Departamento de La Paz, Bolivia. J Selva Andina Res Soc 2: 13-23.

36. Merck. 2016. Hemacolor rapid staining with excellent reproducibility. Darmstadt, Germany. 4 p.

37. Muñoz T, Ayora P, Jiménez V. 2014. Prevalencia de Anaplasma marginale mediante extendidos sanguíneos en el Cantón Zamora, Provincia de Zamora Chinchipe. Rev Salud Anim 3: 44-51.

38. Muñoz-Guarnizo TR, AyoraFernández P, Luzuriaga-Neira A, Corona-González, B, MartínezMarrero S. 2017. Prevalencia de Anaplasma marginale en bovinos de la provincia Zamora Chinchipe, Ecuador. Rev Salud Anim 39: 68-74,

39. Oliveira J, Montoya J, Romero J, Urbina A, Soto-Barrientos N, Melo E, Araújo F. 2011. Epidemiology of bovine anaplasmosis in dairy herds from Costa Rica. Vet Parasitol 177: 359-365. doi: 10.1016/j.vetpar.2010.12.006

40. Orjuela-Cháves J, Cuellar-Silva A, Flórez-Rojas L. 2015. Estabilidad enzoótica de hemoparásitos en terneros de una zona de bosque húmedo tropical del piedemonte amazónico colombiano. Rev FAGROPEC 7: 55-59.
41. Ortega C, de Blas I. 1998. Selección de muestras para el estudio de poblaciones animales en Acuicultura. AquaTIC 3: $1-6$

42. Ortiz M. 2014. Manual con los criterios de aceptación y rechazo de muestras hematológicas para el Laboratorio de Diagnóstico del Instituto Colombiano Agropecuario ICA. Trabajo de Grado. Arauca: Univ. Cooperativa de Colombia. $60 \mathrm{p}$

43. Prada GA, Crespo JC. 2006. Determinación taxonómica de hemoparásitos y su prevalencia en búfalos de agua (Bubalus bubalis) en el Magdalena Medio, Colombia. Rev Invest (Colombia) 6: 67-73.

44. República de Colombia. 1993. Ministerio de Salud. Normas científicas, técnicas y administrativas para la investigación. Resolución No 8430. Bogotá, Colombia. [Internet]. Disponible en: http:// semillas.org.co/es/temas/normas-cient

45. Ríos L, Zapata S, Reyes J, Mejía J, Baena A. 2010. Estabilidad enzoótica de babesiosis bovina en la región de Puerto Berrío, Colombia. Rev Cient-Fac Cien V 20: 485-492.

46. Rodríguez B, Ocaña M, Vargas $H$. 2011. Determinación de enfermedads parasitarias en fincas del área de influencia de la granja Balcanes de la Universidad de la Amazonía. Florencia, CaquetáColombia. Rev Cien Agrop 3: 19-26.

47. Salamanca-Carreño A, Tamasaukas R, Giraldo-Forero JC, Quintero A D, Hernández-Rodríguez ME. 2018. Interacción entre factores ambientales y raciales sobre la prevalencia de hemotrópicos en hembras bovinas doble propósito en sabanas inundables araucanas, Colombia. Rev Cient-Fac Cien V 28: 52-62.

48. Salazar-Benjumea RS. 2015. Variación de la población de garrapatas Rhipicephalus microplus sobre bovinos pastoreando en sistemas silvopastoriles y tradicionales. Tesis de Maestría. Medellín, Colombia: Univ. Nacional de Colombia. 99 p. 
49. Sheen $S$, Riesco A. 2002. Factores que afectan la producción de leche en vacas de doble propósito en el trópico húmedo (Pucallpa). Rev Inv Vet Perú 13: 25-31. doi: 10.15381/rivep.v13i1.1703

50. Souza F, Braga J, Pires L, Carvalho C, Costa Ë, Ribeiro M, Silva S. 2013. Babesiosis and anaplasmosis in dairy cattle in Northeastern Brazil. Pesqui Vet Brasil 33: 1057-1061. doi: 10.1590/ S0100-736X2013000900002

51. Tamasaukas R, Agudo C, Silva R, Florio L, Vintimilla T, Rivera P. 2010. Hemoparásitos en ganadería doble propósito venezolana, diagnóstico y control: una revisión. Agron. Mesoam 21:367-381.
52. Tamasaukas R, Silva A, Florio-Luis J, Sánchez J, Fernández M, Rivera S, Cobo M. 2014. Agroecoepidemiología de tripanosomosis en ganadería doble propósito en el Sistema de Riego Río Guárico, Venezuela. Etapa I. Act Iberoame Conserv Anim 4: 285-288.

53. Useche J. 2010. Prevalencia de hemoparásitos en bovinos de seis veredas del municipio de Purificación-Tolima. Tesis de Médico Veterinario. Bogotá, Colombia: Univ. de la Salle. $84 \mathrm{p}$.

54. Vargas C, Salamanca C. 2013. Diagnóstico preliminar de hemoparásitos en las razas bovinas criolla Casanare y cebú. En: X Encuentro Regional de Semilleros de Investigación. Yopal Casanare. 